\title{
Prevalence and classification of rhinitis in the elderly: a nationwide survey in Portugal
}

\author{
M. Morais-Almeida ${ }^{1,2}$, H. Pite ${ }^{1,2,3}$, A. M. Pereira ${ }^{1,4,5}$, A. Todo-Bom ${ }^{2,6}$, C. Nunes ${ }^{2,7}$, J. Bousquet ${ }^{8}$ \& \\ J. Fonseca $2,4,5,9,10$ \\ ${ }^{1}$ Immunoallergy Department, Hospital CUF-Descobertas and Hospital CUF-Infante Santo, Lisbon; ${ }^{2}$ Sociedade Portuguesa de Alergologia e \\ Imunologia Clínica (SPAIC), Lisbon; ${ }^{3}$ Pharmacology Department, CEDOC, Faculty of Medical Sciences, Lisbon; ${ }^{4}$ Allergy and Clinical \\ Immunology Department, Hospital S. João EPE, Porto; ${ }^{5}$ Health Information and Decision Sciences Department, Faculdade de Medicina da \\ Universidade do Porto, Porto; ${ }^{6}$ Immunoallergy Department, Hospitais da Universidade de Coimbra, Coimbra; ${ }^{7}$ Centro de Imunoalergologia do \\ Algarve, Portimão, Portugal; ${ }^{8}$ Department of Allergy and Respiratory Diseases, University Hospital and INSERM, Montpellier, France; \\ ${ }^{9}$ Allergy Unit, Hospital-CUF Porto and Instituto CUF-Diagnóstico e Tratamento, Porto; ${ }^{10}$ CINTESIS - Center for Research in Health \\ Technologies and Information Systems, Porto, Portugal
}

To cite this article: Morais-Almeida M, Pite H, Pereira AM, Todo-Bom A, Nunes C, Bousquet J, Fonseca J. Prevalence and classification of rhinitis in the elderly: a nationwide survey in Portugal. Allergy 2013; 68: 1150-1157.

\section{Keywords}

ARIA; classification; elderly; prevalence; rhinitis.

\section{Correspondence \\ Mário Morais-Almeida, MD, Department of Immunoallergy, Hospital CUF-Descobertas, Rua Mário Botas 1998-018 Lisbon, Portugal. Tel.: +351-917232267 \\ Fax: $+351-213582301$ \\ E-mail: mmoraisalmeida@netcabo.pt}

Accepted for publication 10 May 2013

DOI:10.1111/all.12207

Edited by: Wytske Fokkens

\begin{abstract}
Background: Nationwide epidemiologic data on rhinitis in the elderly do not exist. This study aimed to estimate the prevalence of rhinitis in the population aged 65 years or above in mainland Portugal and to characterize and classify rhinitis in this age group.

Methods: Cross-sectional, nationwide, population-based survey of citizens aged 65 years or above, living in mainland Portugal. Current rhinitis (CR) was defined as the presence of at least two symptoms: 'repeated sneezing and itchy nose', 'blocked nose for more than one whole hour', or 'runny nose when not having a cold or flu', either usually or in the last 12 months.

Rhinitis severity was assessed using a visual analogue scale; rhinitis was classified according to ARIA.

Results: Data were obtained from 3678 responders (92.5\% response rate). The prevalence of CR was 29.8\% (95\% confidence interval (CI): $28.4 \%-31.3 \%$ ): $49.1 \%$ had mild intermittent, $7.0 \%$ mild persistent, $27.5 \%$ moderate-severe intermittent, and $16.4 \%$ moderate-severe persistent rhinitis. Only $38.6 \%$ of patients with CR had been physician diagnosed and $38.7 \%$ were under treatment for this disease in the previous year. Allergic conjunctivitis symptoms were referred by $68.6 \%$ of subjects with CR (rhinoconjunctivitis population prevalence, $20.5 \%$ (95\% CI: $19.2 \%-21.8 \%)$ ).

Conclusions: Rhinitis and rhinoconjunctivitis are common but underdiagnosed and undertreated diseases in the geriatric population. This was the first nationwide epidemiological survey classifying rhinitis according to ARIA guidelines in this age group. More than $40 \%$ of old-age patients presented moderate-severe disease.
\end{abstract}

\begin{abstract}
Allergic rhinitis is a common chronic respiratory disease, with a reported prevalence of up to $40 \%$ in children and $30 \%$ in adults (1-3). It is frequently associated with allergic conjunctivitis, asthma, and other comorbidities. Considering its high impact on patient's quality of life and economic burden $(4,5)$, allergic rhinitis is regarded as a global public health problem.

In the last decades, the increase in elderly population has been noteworthy in industrialized countries. The increase in
\end{abstract}

life expectancy goes in parallel with a concern for better quality of life. Studies on allergic and respiratory diseases in geriatric populations have shown that allergens, infections, and irritants can be important triggers of inflammation, regardless of age-related physiologic changes in the immune system, connective tissue, and vasculature that may predispose for chronic rhinitis (6-10).

Whereas rhinitis was considered to be highly prevalent in children and young adults, epidemiologic studies suggest that 
it is common in older subjects (11). However, epidemiologic data on rhinitis in the elderly are scarce $(12,13)$. Studies specifically addressing this age group are needed for a proper analysis of rhinitis in geriatrics, allowing better knowledge and raised awareness concerning this disease in the growing elderly population.

This study aimed to estimate the prevalence of rhinitis in the population aged 65 years or above in mainland Portugal and to classify its severity according to ARIA. Secondary aims were to characterize rhinitis symptoms, associated conjunctivitis, and asthma, and to describe the frequency of physician diagnosis and rhinitis medication use.

\section{Methods}

\section{Study design and participants}

Population-based, cross-sectional survey applied by faceto-face interview to citizens aged 65 years or above, living in mainland Portugal.

A stratified (by gender, age, and region), multistep defined sample was used. In a first phase, the number of needed participants from each Portuguese region was defined. This estimation was based on the data from the 2001 Portuguese Census on individuals aged 65 years or above (14) and took into account the second level of the Portuguese Nomenclature of Territorial Units for Statistics (NUTS II), which divides mainland Portugal in five regions: North, Centre, Lisbon and Tagus Valley, Alentejo, and Algarve (Figure S1 represents the distribution of the included elders in each region across mainland Portugal). In a second phase, municipalities were selected within each of the five Portuguese regions until reaching a prespecified number of elder subjects in proportion to the sample size. The selection criteria of municipalities correspond to the aging index, population density, and purchasing power, indicators that summarize the main regional social disparities (14). The distribution by municipalities was based on the levels of differentiation in each region against the factors used to stratify the sample. Population density and purchasing power levels were defined considering the median (national) and standard deviation. The final selection was made using a random-route methodology, where households and nursing homes were included, in each location. (Table S1 shows the comparison between the Portuguese population aged 65 years or above, the predicted sample, and the true sample, considering age, gender, and region).

Informed consent was obtained from all participants. This study's protocol was reviewed and approved by the Ethics Committee of the Hospital CUF-Descobertas, Lisbon, Portugal.

\section{Instruments and data collection}

The instrument for data collection (Table S2) was adapted from the questionnaire used in our previous study (3). A few questions were added regarding age of onset of rhinitis symptoms, physician-diagnosed asthma, and use of medication for asthma treatment. The questionnaire included items previously used in the European Community Respiratory Health Survey (15) (ECRHS) and was adapted to old-age subjects.

Rhinitis severity was assessed using a $0-10$ visual analogue scale (VAS), as previously suggested (16).

Questionnaires were applied by trained interviewers between May and July 2008.

\section{Definitions}

Definitions used in this study are presented in Table 1. In individuals with rhinitis, it was further classified into intermittent/persistent and mild/moderate-severe, according to current ARIA guidelines (4) (Table 1).

\section{Sample size and statistical analysis}

To estimate the prevalence of rhinitis in the elderly Portuguese population, with an expected national prevalence of $25 \%$ and considering an error margin of $1.5 \%$ and a confidence interval of $95 \%$, we would need a sample including 3500 subjects. A nonresponse rate of $12.5 \%$ was assumed. Therefore, 4000 subjects were invited to participate.

Categorical variables were described using absolute and relative frequencies with $95 \%$ confidence intervals $(95 \% \mathrm{CI})$; comparisons were performed using the Pearson's chi-squared test.

Continuous variables were described with mean and standard deviation (SD); for comparisons, an independent samples t-test was used.

A significance level of 5\% was considered.

Multiple logistic regression analysis was used to calculate odds ratios (ORs) with 95\% CI separately for current rhinitis, physician-diagnosed rhinitis, and rhinoconjunctivitis (detailed in Table S3).

Data analyses were performed using SPSS $^{\circledR}$ version 17.0 for Windows (IBM SPSS, Chicago, IL, USA).

\section{Results}

\section{Participants}

A total of 3699 of 4000 invited subjects answered the questionnaire (response rate 92.5\%). There was no evidence of different response rates according to age. From the answered questionnaires, 21 were excluded: 13 subjects were aged $<65$ years and eight had insufficient information due to incomplete interviews. A total of 3678 individuals were included in the analysis (Table S4 - shows the missing data regarding each variable). Participants' socio-demographic characteristics are summarized in Table 2.

\section{Prevalence of current rhinitis, physician-diagnosed rhinitis, and rhinoconjunctivitis}

The prevalence of current rhinitis was $29.8 \%$ (95\% CI: $28.4 \%-31.3 \%$ ). Current rhinitis prevalence was similar in men and women as well as in age groups, and no differences 
Table 1 Definitions used in this study

\begin{tabular}{|c|c|c|}
\hline Variable & Source & Definition \\
\hline Current rhinitis & $\begin{array}{l}\text { Based on ECRHS and } \\
\text { ARIA }(3,4,15)\end{array}$ & $\begin{array}{l}\text { Presence, usually or in the last } 12 \text { months, of at least two of the } \\
\text { following symptoms: 'repeated sneezing and itchy nose'; 'blocked } \\
\text { nose for more than one whole hour'; or 'runny nose when not } \\
\text { having a cold or flu' }\end{array}$ \\
\hline Intermittent rhinitis & Built according to ARIA (4) & $\begin{array}{l}\text { Current rhinitis with nasal symptoms lasting }<4 \text { days in a week or } \\
\text { lasting more than } 4 \text { days/week, but }<4 \text { consecutive weeks }\end{array}$ \\
\hline Persistent rhinitis & Built according to ARIA (4) & $\begin{array}{l}\text { Current rhinitis with nasal symptoms lasting for at least } 4 \text { days in a } \\
\text { week and for more than } 4 \text { consecutive weeks }\end{array}$ \\
\hline Mild rhinitis & Adapted from Bousquet et al. (16) & $\begin{array}{l}\text { Current rhinitis that had a visual analogue scale severity score ranging } \\
\text { between } 0 \text { and } 5\end{array}$ \\
\hline Moderate-severe rhinitis & Adapted from Bousquet et al. (16) & $\begin{array}{l}\text { Current rhinitis that had a visual analogue scale severity score ranging } \\
\text { between } 6 \text { and } 10\end{array}$ \\
\hline Rhinoconjunctivitis & Adapted from ECRHS (15) & $\begin{array}{l}\text { Presence of rhinitis and a positive answer to the question 'Do nasal } \\
\text { symptoms usually occur along with red or itchy-watery eyes?' }\end{array}$ \\
\hline Physician-diagnosed rhinitis & Additional question (3) & $\begin{array}{l}\text { Positive answer to the question 'Has a doctor ever said you have } \\
\text { rhinitis?' }\end{array}$ \\
\hline $\begin{array}{l}\text { Previous performed skin } \\
\text { prick tests }\end{array}$ & Additional question (3) & $\begin{array}{l}\text { Positive answer to the question 'Has a doctor ever asked you to } \\
\text { make skin prick tests?' }\end{array}$ \\
\hline Physician-diagnosed asthma & Adapted from ECRHS (15) & $\begin{array}{l}\text { Positive answer to the question 'Has a doctor ever said you have } \\
\text { asthma?' }\end{array}$ \\
\hline Current treatment for rhinitis & Adapted from ECRHS (15) & $\begin{array}{l}\text { Positive answer to the question 'Have you had any medication for } \\
\text { rhinitis (nasal topical drug or pill) in the last } 12 \text { months?' }\end{array}$ \\
\hline Current treatment for asthma & Adapted from ECRHS (15) & Positive answer to the question 'Do you take medication for asthma?' \\
\hline
\end{tabular}

Table 2 Socio-demographic characteristics of the participants $(n=3678)$

\begin{tabular}{lc}
\hline & $n(\%)$ \\
\hline Gender & \\
$\quad$ Female & $2151(58.5)$ \\
Age, years & \\
$65-74$ & $2128(57.9)$ \\
$75-84$ & $1204(32.7)$ \\
$\geq 85$ & $346(9.4)$ \\
Residency & \\
Own house & $2657(73.2)$ \\
Relatives & $632(17.4)$ \\
Nursing home & $343(9.4)$ \\
Municipality & \\
Urban & $2752(76.5)$ \\
Rural & $845(23.5)$ \\
Portuguese Region & \\
North & $1168(31.8)$ \\
Centre & $789(21.5)$ \\
Lisbon and Tagus Valley & $1271(34.6)$ \\
Alentejo & $284(7.7)$ \\
Algarve & $166(4.5)$ \\
\hline
\end{tabular}

were observed between urban and rural municipalities (Table 3). In two Portuguese regions, current rhinitis prevalence was higher than the national prevalence $(P<0.0001)$ : Alentejo $(57.7 \%)$ and Lisbon and Tagus Valley (35.7\%). In the Algarve (8.4\%) and Centre (14.6\%), current rhinitis prevalence was significantly lower than the national prevalence $(P<0.001)$. Adjusting for independent variables in Table S3, living in Alentejo yielded a high OR, 3.19 (95\% CI: 2.454.17), for current rhinitis, while living in Lisbon and Tagus Valley region was a weak but statistically significant risk for current rhinitis (OR 1.29; 95\% CI: 1.08-1.52). Living in the Centre or in the Algarve was a protective factor for current rhinitis (Table S3).

Physician-diagnosed rhinitis was reported by $38.6 \%$ subjects with current rhinitis (population prevalence 13.1\%, 95\% CI: $12.0 \%-14.2 \%$ ) and $38.7 \%$ had been under treatment for this disease in the previous year. The frequency of current rhinitis among those with physician-diagnosed rhinitis was $87.9 \%$. The prevalence of physician-diagnosed rhinitis was lower than that of current rhinitis in all Portuguese regions (Table 3). This difference was greater in Alentejo, a region associated with a high risk of current rhinitis, but a low risk for physician-diagnosed rhinitis (Table S3).

Symptoms of allergic conjunctivitis were reported by $68.6 \%$ of subjects with current rhinitis, accounting for a prevalence of rhinoconjunctivitis of $20.5 \%$ (95\% CI: $19.2 \%-$ $21.8 \%$ ) in the studied population (Table 3). The risk of rhinoconjunctivitis was dependent on the Portuguese region. Living in a nursing home was significantly associated with current rhinitis, physician-diagnosed rhinitis, and rhinoconjunctivitis (Table S3).

Elders with physician-diagnosed asthma or currently on treatment for asthma presented significantly higher prevalence of current rhinitis, physician-diagnosed rhinitis, and rhinoconjunctivitis (Table 3). In univariate analysis, having physician-diagnosed asthma was strongly associated with all three conditions, in particular with current rhinitis and rhinoconjunctivitis (Table S3). 
Table 3 Prevalence of current rhinitis, physician-diagnosed rhinitis, and rhinoconjunctivitis $(n=3678)$

\begin{tabular}{|c|c|c|c|}
\hline & $\begin{array}{l}\text { Current rhinitis } \\
\%[95 \% \mathrm{Cl}]\end{array}$ & $\begin{array}{l}\text { Physician-diagnosed rhinitis } \\
\%[95 \% \mathrm{Cl}]\end{array}$ & $\begin{array}{l}\text { Rhinoconjunctivitis } \\
\%[95 \% \mathrm{Cl}]\end{array}$ \\
\hline Whole sample & $29.8[28.4-31.3]$ & $13.1[12.0-14.2]$ & 20.5 [19.2-21.8] \\
\hline Gender & $0.086^{*}$ & $0.052^{*}$ & $0.087^{*}$ \\
\hline Male & $28.3[26.0-30.6]$ & $11.8[10.2-13.4]$ & $19.1[17.1-20.1]$ \\
\hline Female & 30.9 [29.0-32.9] & $14.0[12.5-15.5]$ & $21.4[19.7-23.1]$ \\
\hline 65-74 & $30.2[28.3-32.2]$ & $12.6[11.2-14.0]$ & $20.9[19.2-22.6]$ \\
\hline $75-84$ & 28.9 [26.3-31.5] & $14.0[12.0-16.0]$ & $19.3[17.1-21.5]$ \\
\hline$\geq 85$ & 30.9 [26.0-35.8] & 13.1 [9.5-16.7] & 22.3 [17.9-26.7] \\
\hline Municipality & $0.082^{*}$ & $0.207^{*}$ & $0.419 *$ \\
\hline Urban & $30.7[29.0-32.4]$ & $13.5[12.2-14.8]$ & $20.9[19.4-22.4]$ \\
\hline Rural & $27.6[24.6-30.6]$ & $11.9[9.8-14.0]$ & $19.7[17.0-22.4]$ \\
\hline Region & $<0.0001^{*}$ & $<0.0001^{*}$ & $<0.0001^{*}$ \\
\hline Centre & $14.6[12.1-17.1]$ & 9.5 [7.5-11.6] & $8.7[6.7-10.7]$ \\
\hline Lisbon and Tagus Valley & $35.7[33.1-38.3]$ & $15.0[13.0-17.0]$ & $24.4[22.0-26.8]$ \\
\hline Alentejo & $57.7[52.0-63.5]$ & $5.3[2.7-7.9]$ & 33.8 [28.3-39.3] \\
\hline Algarve & $8.4[4.2-12.6]$ & $4.8[1.5-8.1]$ & $4.2[1.2-7.3]$ \\
\hline Physician-diagnosed asthma & $<0.0001^{*}$ & $<0.0001^{*}$ & $<0.0001^{*}$ \\
\hline Absent & $23.6[22.2-25.1]$ & $9.7[8.7-10.7]$ & 14.6 [13.4-15.8] \\
\hline Present & $81.1[77.3-84.9]$ & $40.9[36.1-45.7]$ & $68.3[63.8-72.9]$ \\
\hline Current treatment for asthma & $<0.0001^{*}$ & $<0.0001^{*}$ & $<0.0001^{*}$ \\
\hline Absent & $25.7[24.2-27.2]$ & $12.2[11.1-13.3]$ & $16.3[15.1-17.5]$ \\
\hline Present & 86.6 [82.6-90.6] & 39.8 [34.1-45.5] & 71.7 [66.4-77.0] \\
\hline
\end{tabular}

* $P$-value.

\section{Rhinitis characterization and classification}

Among participants classified as having current rhinitis, the most commonly reported symptom was 'runny nose when not having a cold or flu' $(31.1 \%)$, followed by 'repeated sneezing and itchy nose' $(30.0 \%$; Fig. 1$) ; 22.5 \%$ reported to have all the questioned symptoms either usually or in the last 12 months.

In $39.0 \%$ of these individuals, rhinitis symptoms had started between 20 and 40 years of age; $19.6 \%$ reported that rhinitis symptoms started before the age of $20,16.5 \%$ between 40 and 60 years, and $4.6 \%$ after the age of 60 (20.3\% did not know/did not answer). The overall symptom duration was of more than 25 years in $60.1 \%$ of the elders. There were no significant gender differences in the age of onset of rhinitis symptoms.

Nasal symptoms were present for more than 4 days per week in $42.8 \%$ of cases and more than 4 weeks in a year in $50.8 \%$. The mean (SD) value for rhinitis severity, considering the $0-10$ VAS, was $4.9(2.3)$. The overall VAS results are presented in Fig. 2.

Rhinitis was classified as mild intermittent in $49.1 \%$ of all cases, moderate-severe intermittent in $27.5 \%$, mild persistent in $7.0 \%$, and moderate-severe persistent in $16.4 \%$. The prevalence of each rhinitis type and its characterization are expressed in Table 4. Elderly subjects living in urban regions had a higher prevalence of moderate-severe intermittent and mild persistent rhinitis, while those living in rural regions had

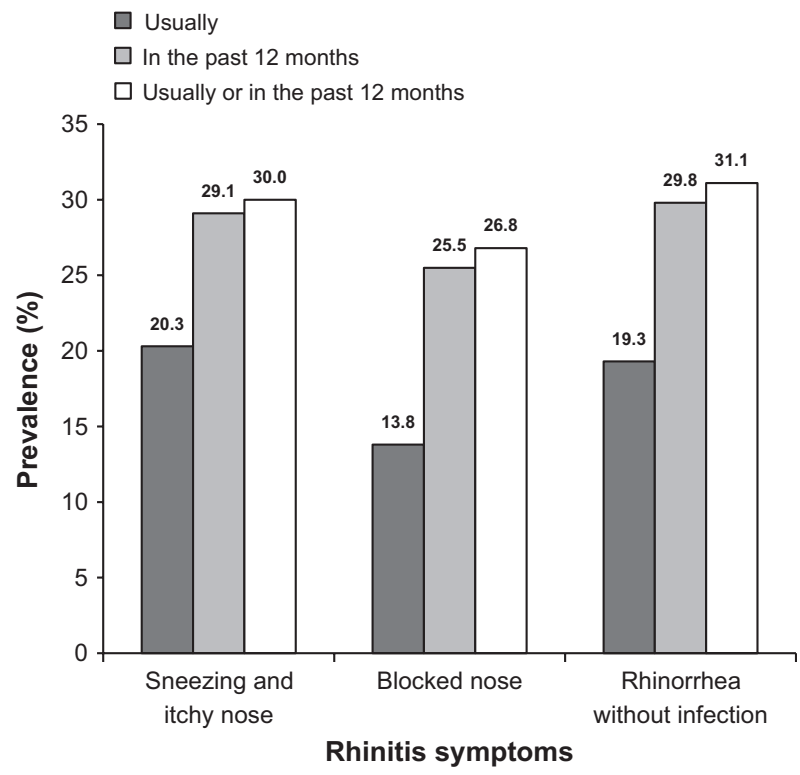

Figure 1 Prevalence of rhinitis symptoms reported either usually or in the past 12 months ( $n=3678$ ).

higher frequency of moderate-severe persistent rhinitis (Table 4). Two Portuguese regions, Alentejo and Lisbon and Tagus Valley, presented higher prevalence of intermittent 
rhinitis, compared with the other regions $(57.0 \%$ vs $19.6 \%$ and $30.1 \%$ vs $18.4 \%$, respectively, $P<0.0001$ ). Those elders living in the North had higher prevalence of persistent rhinitis $(11.9 \%$ vs $4.5 \%, P<0.0001)$, and elders living in the Algarve presented lower prevalence of all classes of rhinitis (Table 4).

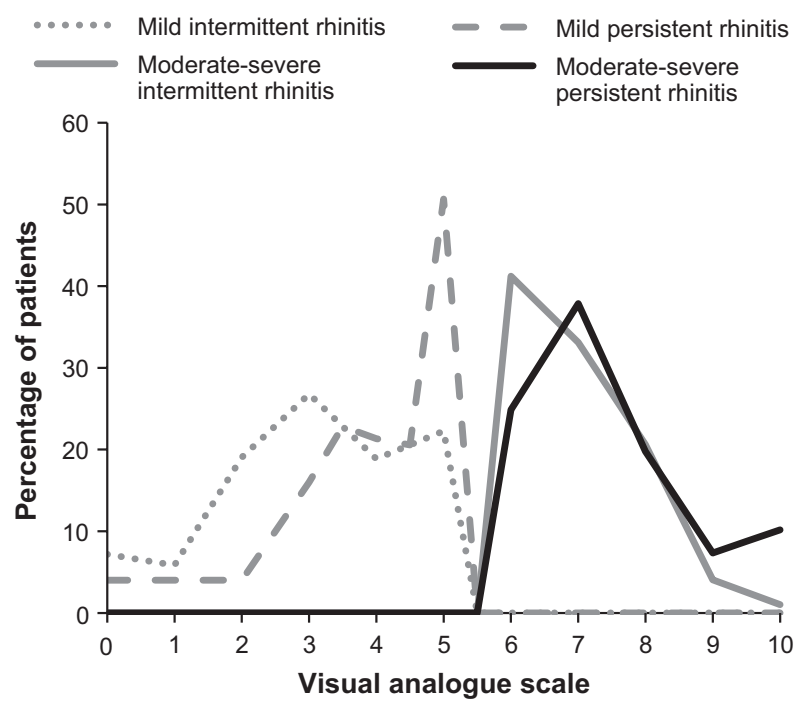

Figure 2 Distribution of patients according to visual analogue scale results in each ARIA class.
Individuals with physician-diagnosed asthma and those on current treatment for asthma, when compared with those without, presented higher prevalence of all classes of rhinitis, including mild intermittent (Table 4).

Physician-diagnosed rhinitis and previously performed skin prick tests were more frequent in elderly people with moderate-severe rhinitis $(57.4 \%$ vs $23.6 \%$ and $70.2 \%$ vs $50.4 \%$ in mild rhinitis, respectively, $P<0.0001)$ and in those with persistent rhinitis $(80.2 \%$ vs $25.5 \%$ and $75.4 \%$ vs $54.1 \%$ in intermittent rhinitis, respectively, $P<0.0001)$. Likewise, rhinitis treatment in the previous year was more frequent in elderly people with moderate-severe rhinitis $(56.9 \%$ vs $24.1 \%$ in mild rhinitis, $P<0.0001)$ and in those with persistent rhinitis $(80.2 \%$ vs $25.8 \%$ in intermittent rhinitis, $P<0.0001)$.

Rhinoconjunctivitis was also more frequent in subjects with moderate-severe $(83.7 \%$ vs $57.0 \%$ in mild rhinitis, $P<0.0001)$ and persistent rhinitis $(92.0 \%$ vs $61.6 \%$ in intermittent rhinitis, $P<0.0001)$.

\section{Discussion}

In the Portuguese population aged 65 years or above, we found a high prevalence of current rhinitis and of rhinoconjunctivitis $-29.8 \%$ and $20.5 \%$, respectively. Furthermore, this study showed that these diseases were underdiagnosed and undertreated in this age group, despite a overall symptom duration of more than 25 years in the majority of subjects and that almost half had moderate-severe disease.

Table 4 Prevalence of rhinitis according to classification categories $(n=3678$ )

\begin{tabular}{|c|c|c|c|c|}
\hline & $\begin{array}{l}\text { Mild intermittent } \\
\%[95 \% \mathrm{Cl}]\end{array}$ & $\begin{array}{l}\text { Moderate-severe intermittent } \\
\%[95 \% \mathrm{Cl}]\end{array}$ & $\begin{array}{l}\text { Mild persistent } \\
\%[95 \% \mathrm{Cl}]\end{array}$ & $\begin{array}{l}\text { Moderate-severe persistent } \\
\%[95 \% \mathrm{Cl}]\end{array}$ \\
\hline Whole sample & $14.4[13.3-15.5]$ & $8.1[7.2-9.0]$ & $2.0[1.6-2.5]$ & $4.8[4.1-5.5]$ \\
\hline Gender & $0.846^{*}$ & $0.113^{*}$ & $0.788^{*}$ & $0.483^{*}$ \\
\hline Male & $14.3[12.5-16.1]$ & $7.2[5.9-8.5]$ & $2.0[1.3-2.7]$ & $4.5[3.5-5.5]$ \\
\hline Female & $14.5[13.0-16.0]$ & $8.6[7.4-9.8]$ & $2.1[1.5-2.7]$ & $5.0[4.1-5.9]$ \\
\hline Age, years & $0.155^{*}$ & $0.041^{*}$ & $0.936^{*}$ & $0.835^{*}$ \\
\hline 65-74 & $15.3[13.8-16.8]$ & $7.7[6.6-8.8]$ & $2.0[1.4-2.6]$ & $4.7[3.8-5.6]$ \\
\hline $75-84$ & $13.6[11.7-15.5]$ & $7.7[6.2-9.2]$ & $2.2[1.4-3.0]$ & 5.1 [3.9-6.3] \\
\hline$\geq 85$ & $11.8[8.4-15.2]$ & $11.6[8.2-15.0]$ & $2.0[0.5-3.5]$ & $4.3[2.2-6.4]$ \\
\hline Municipality & $0.837^{*}$ & $<0.0001^{*}$ & $0.004^{*}$ & $<0.0001^{*}$ \\
\hline Urban & $14.4[13.1-15.7]$ & $9.4[8.3-10.5]$ & $2.4[1.8-3.0]$ & $4.1[3.4-4.8]$ \\
\hline Rural & $14.7[12.3-17.1]$ & $3.9[2.6-5.2]$ & $0.8[0.2-1.4]$ & $7.3[5.6-9.1]$ \\
\hline Region & $<0.0001^{*}$ & $<0.0001^{*}$ & $0.017^{*}$ & $<0.0001^{*}$ \\
\hline Centre & $6.8[5.0-8.6]$ & $2.2[1.2-3.2]$ & $2.0[1.0-3.0]$ & $3.2[2.0-4.4]$ \\
\hline Lisbon and Tagus Valley & $17.0[14.9-19.1]$ & $13.1[11.3-15.0]$ & $1.6[0.9-2.3]$ & $3.8[2.8-4.9]$ \\
\hline Alentejo & 37.7 [32.1-43.3] & $19.4[14.8-24.0]$ & $0.7[0.1-2.5]$ & $0.0[0.0-1.1]$ \\
\hline Algarve & $4.8[1.6-8.1]$ & $1.8[0.7-3.7]$ & $0.6[0.0-3.3]$ & $0.0[0.0-1.8]$ \\
\hline Physician-diagnosed asthma & $<0.0001^{*}$ & $<0.0001^{*}$ & $<0.0001^{*}$ & $<0.0001^{*}$ \\
\hline Absent & $12.9[11.8-14.1]$ & $6.3[5.5-7.1]$ & $1.5[1.1-1.9]$ & $2.4[1.9-2.9]$ \\
\hline Present & $26.7[22.4-31.0]$ & $22.7[18.6-26.8]$ & $6.2[3.8-8.6]$ & $24.2[20.0-28.4]$ \\
\hline Current treatment for asthma & $<0.0001^{*}$ & $<0.0001^{*}$ & $<0.0001^{*}$ & $<0.0001^{*}$ \\
\hline Absent & $13.6[12.5-14.8]$ & $6.7[5.9-7.5]$ & $1.7[1.3-2.1]$ & $3.3[2.7-3.9]$ \\
\hline Present & $24.7[19.6-29.8]$ & $24.7[19.6-29.8]$ & $6.5[3.6-9.4]$ & $23.7[18.7-28.7]$ \\
\hline
\end{tabular}

* P-value. 
The frequency of rhinitis in the elderly has been addressed in very few elderly-targeted studies. Ventura et al. (17) found that rhinitis was present in $16.8 \%$ of the patients aged over 65 years referred to an allergology unit. Population-based studies are even scarcer. Only one study performed in Mexico City has shown that allergic rhinitis was present in $3.6 \%$ of 333 elderly subjects who were attending a social security recreative center (12). In general epidemiologic studies, subgroup analysis reported rhinitis prevalence between $16.1 \%$ and $25.9 \%$ in the elderly $(3,18-20)$. However, different selection criteria and rhinitis definitions restrict interstudy comparisons.

Although limited by the lack of physician diagnosis confirmation, our study is truly population based, nationwide, and targeted to this specific age group. The sampling strategy allowed that the number of individuals of each gender, age, and Portuguese region is reliably correspondent to the structure of the resident population in mainland Portugal (aged 65 years or above), according to the data from the 2001 National Census (14). Moreover, this is the first large population-based study reporting rhinitis classification according to ARIA guidelines in this age group.

The definition of current rhinitis used in the present study, combining at least two nasal symptoms, is suggestive of allergic rhinitis (4). This was further reinforced as there were associated symptoms of red, itchy eyes and tearing (4), reported by the majority of our cases. However, nonallergic conditions may cause similar symptoms, such as irritants, atrophic, drug-induced, or infectious rhinitis (4). Therefore, allergic rhinitis was not defined, as this was only a questionnaire-based survey, not including any demonstration of specific immunopathologic mechanisms. Still, this definition of rhinitis was important to exclude some of other causes, such as the so-called rhinitis of the elderly, characterized by clear rhinorrhea without other nasal symptoms (4).

Our present findings are in agreement with our previous study reporting rhinitis prevalence in adults in Portugal (3). That study, using questions and a rhinitis definition that were similar to those used in the present report, found high rhinitis prevalence in adults aged $16-95$ years $(26.1 \%)$. In the same study (3), a subpopulation analysis found that rhinitis prevalence in subjects aged above 65 years was $25.9 \%$. The higher prevalence observed in the present study (29.8\%) may reflect either a more accurate estimation of rhinitis in the elderly or an actual increasing tendency in rhinitis prevalence in this age group over the last years. A recent nationwide epidemiologic study performed in 2010 in Portugal, including individuals from all age groups and reporting rhinitis prevalence as a secondary aim, found that $22.1 \%$ of included subjects had rhinitis (21). However, direct comparisons are limited because different sampling and definitions for rhinitis were used.

Furthermore, we found a higher prevalence of rhinoconjunctivitis than that previously reported in adults (18.4\%) (3); this finding is in agreement with a recent study, suggesting that elderly patients have rhinitis plus conjunctivitis more frequently than young adults (22).
The most common nasal symptom in elders with current rhinitis was watery rhinorrhea, which differs from studies in allergic rhinitis in adults (3), where sneezing and itchy nose were the most reported symptoms. This may be due to concomitant age-related changes in nasal physiology in the elderly (nasal glandular atrophy, vascular changes, decreased nasal humidification, decreased mucociliary clearance, and structural changes of the nose) $(7,8,10,23)$, which may contribute to more frequent rhinorrhea. In fact, it is likely that several mechanisms underlie the pathogenesis of rhinitis in the elderly, with potential interaction between inflammatory conditions and the influence of aging on nasal physiology (24).

As defined by ARIA, we found that $49.1 \%$ of the elders had mild intermittent rhinitis, $7.0 \%$ mild persistent rhinitis, $27.5 \%$ moderate-severe intermittent rhinitis, and $16.4 \%$ moderate-severe persistent rhinitis. Cross-sectional and longitudinal studies have shown that rhinitis symptoms become milder with age (24-26). However, in this study, more than $40 \%$ of the elders with rhinitis presented moderate-severe disease.

Our data emphasize a significant low prevalence of physician diagnosis, previous diagnostic skin prick tests, and treatment for rhinitis. This is especially relevant in the considerable group of older adults reporting moderate-severe symptoms who lack physician diagnosis and treatment. It was interesting to notice that, after adjusting for independent variables, living in nursing homes was associated with current rhinitis, rhinoconjunctivitis, and also with physician-diagnosed rhinitis. Despite more symptomatic, living in a nursing home may foster better access to health care.

We also found regional differences across mainland Portugal. Living in Alentejo or in Lisbon and Tagus Valley region was a significant risk of current rhinitis. The greater difference between current rhinitis and physician-diagnosed rhinitis prevalence was observed in Alentejo. This may be related to the fact that the vast majority of elders living in this region had intermittent rhinitis $(98.8 \%)$, but may also reflect lower access to health care in this area. Alentejo is an inland region, also characterized by the highest absolute pollen concentrations in mainland Portugal, which occur seasonally, due fundamentally to the pollination of Poaceae (27). This may be associated with the high frequency of intermittent rhinitis we observed in this region.

Although overall rhinitis prevalence did not differ between elders living in rural or urban regions, those living in a rural region had a higher prevalence of moderate-severe persistent rhinitis. This was an unexpected result. Several studies have found that the prevalence of allergic rhinitis is higher in urban than in rural areas (28-30). Moreover, in our previous study in adults (3), rural inhabitants presented significantly higher levels of intermittent rhinitis. It is possible that confounding factors, such as lifetime changes in the living region (from urban to rural regions and vice versa), may contribute to these results.

The importance of the underdiagnosis of rhinitis is further reinforced by the association we observed between all ARIA classes of rhinitis and asthma in this age group. Current rhinitis and rhinoconjunctivitis were strongly associated with 
physician-diagnosed asthma. Although only self-reported, physician-diagnosed asthma was studied, our results support an extensive nose-lung interaction in older individuals, as observed by others $(9,31-33)$. This association may justify the importance of rhinitis physician diagnosis, including in milder forms of the disease.

Addressing rhinitis in the geriatric population is recognized as an important existing unmet need (4), especially considering the increase in the elderly population throughout Europe together with the aim to stimulate active, healthy aging. The present study reveals that rhinitis and rhinoconjunctivitis are highly prevalent but underdiagnosed and undertreated diseases in the elderly population, despite that over $40 \%$ have moderate-severe disease.

\section{Acknowledgments}

Methodological support and fieldwork was supplied by KeyPoint, Scientific Consultants.

This study was supported by a Schering-Plough Pharma grant attributed to Sociedade Portuguesa de Alergologia e Imunologia Clínica (SPAIC).

\section{Author contributions}

HP participated in data analysis and interpretation and wrote the manuscript draft, AMP participated in data interpretation and review, ATB and CN participated in the study conception, JB provided critical review during the project, JAF participated in data analysis and interpretation and provided critical review during the project, and MMA coordinated the study participating in all stages and tasks. All authors have reviewed and approved the final manuscript.

\section{Conflicts of interest}

Mário Morais-Almeida (MMA) received travel grants, speaking fees, and honoraria for advisory boards from Astrazeneca, GSK, FAES Farma, MSD, Novartis, OM Pharma, Pfizer, Sanofi, Schering-Plough, Siemens Diagnostics. Ana Todo-Bom (ATB) received travel grants, speaking fees, and honoraria for advisory boards from GSK, FAES Farma, MSD, Novartis. Jean Bousquet (JB) received honoraria for scientific and advisory boards, lectures during meetings, press conferences from Stallergènes, Actelion, Almirall, AstraZeneca, Chiesi, GSK, Merck, MSD, Novartis, OM Pharma, Sanofi-Aventis, Schering-Plough, Teva, Uriach. João Almeida Fonseca (JAF) has received an unrestricted research grant from Aerocrine AB and honoraria for travel grants, speaking fees, and advisory boards from Astrazeneca, GSK, MSD, and Novartis. Helena Pité (HP), Ana Margarida Pereira (AMP), and Carlos Nunes (CN) have no conflicts of interest to declare.

\section{Supporting Information}

Additional Supporting Information may be found in the online version of this article:

Table S1. Comparison between the Portuguese population aged 65 years or above, the predicted sample, and the true sample, considering age, gender, and region.

Table S2. Study's questionnaire.

Table S3. Univariate (unadjusted) and multivariate (adjusted) analysis for risk of 'current rhinitis', 'physiciandiagnosed rhinitis', or 'rhinoconjunctivitis'.

Table S4. Missing data.

Figure S1. Distribution of the included elders in each region across mainland Portugal.

\section{References}

1. Bauchau V, Durham SR. Prevalence and rate of diagnosis of allergic rhinitis in Europe. Eur Respir J 2004;24:758-764.

2. Asher MI, Montefort S, Bjorksten B, Lai CK, Strachan DP, Weiland SK et al. Worldwide time trends in the prevalence of symptoms of asthma, allergic rhinoconjunctivitis, and eczema in childhood: ISAAC Phases One and Three repeat multicountry cross-sectional surveys. Lancet 2006;368:733-743.

3. Todo-Bom A, Loureiro C, Almeida MM, Nunes C, Delgado L, Castel-Branco G et al. Epidemiology of rhinitis in Portugal: evaluation of the intermittent and the persistent types. Allergy 2007;62:1038-1043.

4. Bousquet J, Khaltaev N, Cruz AA, Denburg J, Fokkens WJ, Togias A et al. Allergic Rhinitis and its Impact on Asthma (ARIA) 2008 update (in collaboration with the World Health Organization, GA(2)LEN and AllerGen). Allergy 2008;63(Suppl 86):8-160.

5. Weir E. The burden of rhinitis: nothing to sniff at. CMAJ 2003;169:694.
6. Slavin RG. Allergic rhinitis: managing the adult spectrum. Allergy Asthma Proc 2006;27:9-11.

7. Edelstein DR. Aging of the normal nose in adults. Laryngoscope 1996;106:1-25.

8. Vignola AM, Scichilone N, Bousquet J, Bonsignore G, Bellia V. Aging and asthma: pathophysiological mechanisms. Allergy 2003;58:165-175.

9. Huss K, Naumann PL, Mason PJ, Nanda JP, Huss RW, Smith CM et al. Asthma severity, atopic status, allergen exposure and quality of life in elderly persons. Ann Allergy Asthma Immunol 2001;86:524-530.

10. Bellanti JA, Azem M, MacDowell-Carneiro AL, Tutuncuoglu SO, Wallerstedt DB. Possible mechanisms of late-life-onset allergic diseases and asthma in the senior citizen. Allergy Asthma Proc 2000;21:267-270.

11. Jarvis D, Newson R, Lotvall J, Hastan D, Tomassen P, Keil T et al. Asthma in adults and its association with chronic rhinosinusitis: the GA2LEN survey in Europe. Allergy 2012;67:91-98.
12. Becerril Angeles M, Vazquez Merino CL, Angeles Garay U, Alvarado Moctezuma LE, Vilchis Guizar E. [Prevalence of allergic diseases in the elderly]. Rev Alerg Mex 2008;55:85-91.

13. Bousquet J, Schunemann HJ, Samolinski B, Demoly P, Baena-Cagnani CE, Bachert C et al. Allergic Rhinitis and its Impact on Asthma (ARIA): achievements in 10 years and future needs. J Allergy Clin Immunol 2012;130:1049-1062.

14. Instituto Nacional de Estatística. Censos 2001: Resultados definitivos. XIV Recenseamento geral da População. Lisbon: INE, 2002.

15. The European Community Respiratory Health Survey II Steering Committee. The European Community Respiratory Health Survey II. Eur Respir J 2002;20:1071-1079.

16. Bousquet PJ, Combescure C, Neukirch F, Klossek JM, Mechin H, Daures JP et al. Visual analog scales can assess the severity of rhinitis graded according to ARIA guidelines. Allergy 2007;62:367-372. 
17. Ventura MT, D'Amato A, Giannini M, Carretta A, Tummolo RA, Buquicchio R. Incidence of allergic diseases in an elderly population. Immunopharmacol Immunotoxicol 2010;32:165-170.

18. Eriksson J, Ekerljung L, Pullerits T, Holmberg K, Ronmark E, Lotvall J et al. Prevalence of chronic nasal symptoms in West Sweden: risk factors and relation to self-reported allergic rhinitis and lower respiratory symptoms. Int Arch Allergy Immunol 2011;154:155-163.

19. Konno S, Hizawa N, Fukutomi Y, Taniguchi M, Kawagishi Y, Okada $\mathrm{C}$ et al. The prevalence of rhinitis and its association with smoking and obesity in a nationwide survey of Japanese adults. Allergy 2012;67:653-660.

20. Sichletidis L, Tsiotsios I, Gavriilidis A, Chloros D, Kottakis I, Daskalopoulou E et al. Prevalence of chronic obstructive pulmonary disease and rhinitis in northern Greece. Respiration 2005;72:270-277.

21. Sa-Sousa A, Morais-Almeida M, Azevedo LF, Carvalho R, Jacinto T, Todo-Bom A et al. Prevalence of asthma in Portugal The Portuguese National Asthma Survey. Clin Transl Allergy 2012;2:15.
22. Ventura MT, Gelardi M, D'Amato A, Buquicchio R, Tummolo R, Misciagna G et al. Clinical and cytologic characteristics of allergic rhinitis in elderly patients. Ann Allergy Asthma Immunol 2012;108:141-144.

23. Garcia GJ, Bailie N, Martins DA, Kimbell JS. Atrophic rhinitis: a CFD study of air conditioning in the nasal cavity. $J$ Appl Physiol 2007;103:1082-1092.

24. Pinto JM, Jeswani S. Rhinitis in the geriatric population. Allergy Asthma Clin Immunol 2010;6:10.

25. Simola M, Holopainene E, Malmberg $\mathrm{H}$. Changes in skin and nasal sensitivity to allergens and the course of rhinitis; a longterm follow-up study. Ann Allergy Asthma Immunol 1999;82:152-156.

26. Karakaya G, Kalyoncu AF. The natural course of atopy determined by skin prick tests in patients with bronchial asthma and/ or rhinitis. Allergol Immunopathol (Madr) 2006;34:257-262.

27. Caeiro E, Brandão R, Carmo S, Lopes L, Morais-Almeida M, Gaspar A et al. The Portuguese Aerobiology Network: airborne pollen results (2002-2006). Rev Port Imunoalergologia 2007;15:235-250.
28. Nicolaou N, Siddique N, Custovic A. Allergic disease in urban and rural populations: increasing prevalence with increasing urbanization. Allergy 2005;60:1357-1360.

29. Charpin D, Sibbald B, Weeke E, Wuthrich B. Epidemiologic identification of allergic rhinitis. Allergy 1996;51:293-298.

30. von Mutius E, Martinez FD, Fritzsch C, Nicolai T, Roell G, Thiemann HH. Prevalence of asthma and atopy in two areas of West and East Germany. Am J Respir Crit Care Med 1994;149:358-364.

31. Eriksson J, Bjerg A, Lotvall J, Wennergren G, Ronmark E, Toren K et al. Rhinitis phenotypes correlate with different symptom presentation and risk factor patterns of asthma. Respir Med 2011;105:1611-1621.

32. Shaaban R, Zureik M, Soussan D, Neukirch C, Heinrich J, Sunyer J et al. Rhinitis and onset of asthma: a longitudinal population-based study. Lancet 2008;372:1049-1057.

33. Passalacqua G, Ciprandi G, Canonica GW. The nose-lung interaction in allergic rhinitis and asthma: united airways disease. Curr Opin Allergy Clin Immunol 2001;1:7-13. 